\title{
La producción del scriptorium alfonsí
}

\section{Daniel GRÉGORIO}

Universidad de Valenciennes

La producción intelectual del scriptorium alfonsí, una producción que, como ya se puede suponer es la causa de que se atribuyera a Alfonso $\mathrm{X}$ el epíteto de Sabio y por la que se ha calificado su reinado de auténtico renacimiento alfonsí.

Sin embargo, es difícil, incluso imposible, comprender una obra sin tener en cuenta la personalidad del autor y el contexto en el que fue realizada.

Empezaremos, pues, por una rápida biografía de Alfonso X para describir después brevemente la situación política en la que se encontraba el reino de Castilla en el siglo XIII. A partir de entonces podremos comprender mejor la mentalidad de aquella época y sobre todo las técnicas de trabajo así como los objetivos generales que se querían alcanzar. No se trata sólo de evocar lo que se creó o se escribió, sino también la forma en que se transmitía el conocimiento, la cultura de aquella época, los métodos para crear, dentro de los cánones medievales, por supuesto. Paradójicamente, ello nos obligará a destruir, o por lo menos matizar, el mito de Alfonso X como autor.

Hijo de Fernando III, el santo, y de Beatriz de Suabia, Alfonso X subió al trono castellano en 1252 a la edad de 31 años. Su reino estuvo marcado por hechos guerreros, por una intensa actividad política centrada en la obtención de la corona imperial y sobre todo por una extensa actividad cultural.

El siglo XIII representa un hito en la Reconquista desde un punto de vista militar, sin aportar una paz estable y duradera. Tras la victoria de las Navas de Tolosa en 1212, los reinos cristianos prosiguieron su expansión hacia el sur. Así, Jaime I tomó Valencia (1238), mientras Fernando III ocupaba sucesivamente las ciudades de Córdoba (1238) de Murcia (1243) de Jaén (1246) y de Sevilla (1246).

Una vez coronado, Alfonso X, que ya había participado en la toma de Murcia, extendió sus dominios hasta Jerez de la Frontera (1253) y terminó por someter el reino de Niebla (1262) y conquistar la ciudad de Cádiz (1263). A estos hechos se añadió un intento de cruzada en ultramar. En efecto, en 1260, el monarca envió una expedición para conquistar la ciudad de Salé, cerca de Rabat. Aunque las tropas castellanas tomaron la ciudad, la invasión fue un desastre y quince días después de la conquista de Salé, los castellanos tuvieron que abando- 


\section{Daniel Grégorio}

narla ante la presión del emir Abu Yusuf Yaqub b. Abd al-Haqq. Por supuesto, este revés militar no significó ni mucho menos una amenaza seria para la corona castellana, que tuvo que afrontar peligros mayores en los años siguientes. Así ocurrió en 1264, cuando los mudéjares de Jerez de la Frontera, de Medina y de Murcia, con el apoyo directo del rey de Granada (Muhamad I ibn al-Ahmar), se rebelaron contra Castilla. Esta rebelión, neutralizada en 1265, indica que si las fronteras castellanas parecían consolidadas, la Reconquista estaba lejos de haberse acabado.

La aparente estabilidad de sus fronteras incitó a Alfonso X a implicarse de lleno en una política internacional que, entre 1256 y 1273, se identificó con el Fecho del Imperio.

Tras la muerte de Federico II en 1250 y de su hijo Conrado IV en 1254, el trono imperial quedó vacío. Al ser Alfonso X biznieto de Federico I Barbarroja, por parte de su madre, las ciudades de Pisa y de Marsella apoyaron las pretensiones del rey al trono imperial en 1256. Este apoyo era insuficiente, pues el nombramiento imperial debía ser otorgado por los electores alemanes y respaldado por el papado. En 1257 tuvo lugar una doble elección, ya que los nobles alemanes dividieron sus votos entre el rey castellano y Ricardo de Cornualles. Aunque Alfonso X reclamaba la corona imperial y esperaba obtener el apoyo del papado, no pudo vencer los recelos de Roma que veía en él el heredero directo de su mayor enemigo, la familia Staufen. Fue justamente esta desconfianza la que hizo que los diferentes pontífices no reconocieran la elección del rey castellano, incluso tras la muerte de su rival en 1272.

Alfonso X empezó a gastar cuantiosas sumas de dinero para intentar comprar los votos de los demás electores, mientras desarrollaba también una política exterior e interior acorde con un título imperial que aún no poseía. Pero a pesar de ello, y tal vez incluso a causa de la labor cultural que llevó a cabo en su corte, Roma siempre le negó su apoyo hasta que, en 1273, Gregorio X apoyó a Rodolfo de Habsburgo, que fue elegido emperador casi inmediatamente.

Se acabó así el sueño imperial de Alfonso X, aunque aún tenía que conocer mayores decepciones en el interior de su propio reino.

Quedaría fuera del objetivo que nos hemos fijado aquí desarrollar todas las causas económicas y políticas que originaron la oposición nobiliaria contra el rey.

Retendremos únicamente que, ya en 1269, los nobles empezaron a quejarse ante los gastos excesivos realizados para los preparativos de la boda del infante Don Fernando de la Cerda. Por otra parte, la vo- 
luntad de aplicar una ley común, plasmada en el Fuero Real y las Siete Partidas, además de los graves problemas económicos causados por los gastos ocasionados por los proyectos imperiales del monarca, enrarecieron el clima político de la época.

Pese a los acuerdos obtenidos en las Cortes de Burgos de 1272, en los que el monarca accedió a algunas demandas de los nobles, posponiendo su proyecto de implantar una legislación única en todo su reino, el propio hermano del rey, don Felipe, llegó a romper su homenaje hacia Alfonso X para ofrecerlo al rey de Granada.

La auténtica crisis llegó con la muerte inesperada de Fernando de la Cerda (1275), el heredero del rey. Su hijo, Alfonso de la Cerda sólo tenía cinco años, y por lo tanto se planteó la posibilidad de reconocer a don Sancho, hijo segundo del rey que contaba ya diecisiete años, como heredero de la corona, evitando así un período de regencia en el que el poderío castellano podría debilitarse. La reciente victoria de don Sancho contra los benimerines, que subrayó más aún sus aptitudes como dirigente, y la necesidad para el reino de tener una línea sucesoria segura favorecieron su elección como heredero de la corona en 1276.

Esta elección provocó el descontento de los partidarios de Alfonso de la Cerda, nieto de Alfonso X y de Felipe III de Francia. Tal vez fue la presión política o la simple noción de justicia real lo que hizo que, en 1281, en las cortes de Sevilla, el rey decidió atribuir el reino de Jaén a su nieto Alfonso de la Cerda. Para don Sancho, que desde 1278 había ido asumiendo poco a poco la dirección del reino, ello era inaceptable, pues significaba una merma considerable de su propio reino. Por otra parte, en aquella época la enfermedad ya había alterado considerablemente la personalidad del monarca, causando graves enfrentamientos con su mujer Violante o empujándolo a ejecutar a su propio hermano don Fadrique sin que se sepa a ciencia cierta por qué.

Padre e hijo se enfrentaron a partir de entonces, el primero pensando que el segundo estaba organizando una conjura para destronarlo, y éste considerando que la enfermedad de aquél le imposibilitaba para gobernar. En 1282, don Sancho convocó una reunión en Valladolid; no fueron exactamente unas Cortes Generales, puesto que no fueron convocadas ni presididas por el rey, pero en ellas estaban presentes todos los que habitualmente acudían al llamado del monarca, desde la reina hasta los obispos, pasando por los grandes maestres de las órdenes de caballería. Todas las ciudades mandaron representantes, salvo Toledo y Sevilla. Estas Cortes, dieron todo el poder real a don Sancho, aunque sin el título de rey, puesto que Alfonso X todavía vi- 


\section{Daniel Grégorio}

vía. La amargura de esta oposición no pudo desaparecer del todo, incluso cuando padre e hijo se reconciliaron, por lo menos oficialmente, poco antes de la muerte del rey en 1284

Estos hechos históricos tuvieron repercusiones en el ámbito intelectual, y no deben hacernos olvidar las otras facetas de la sociedad castellana del reinado alfonsí.

A menudo, la España medieval es considerada, sin razón, únicamente como la España de la Reconquista. Por supuesto, este contexto guerrero marcó, como lo hemos visto, la política de la época y terminó por impregnar significativamente la literatura, la arquitectura y el folclore hispánico, pero no debería hacernos olvidar la España de las tres religiones, o mejor aún la España de las tres culturas que, durante casi siete siglos, cohabitaron con mayor o menor intensidad. Si algunas joyas de la arquitectura, como las catedrales de Santiago y de León o la Alhambra, son el resultado de una creación cristiana o musulmana, otras, sobre todo en el ámbito de las ideas y de la reflexión, son el producto de una colaboración, directa y a veces indirecta, de una transmisión de saberes entre las diferentes tradiciones.

Esta colaboración alcanzó justamente su paroxismo en la corte de Alfonso X de Castilla.

Pese a la guerra, durante su reinado hubo una colaboración nada desdeñable entre las tres culturas. Esta circunstancia se debió sin duda al espíritu inquieto del monarca pero también a su voluntad por honrar el título de emperador al que aspiraba. Seguramente inspirado por el ejemplo de los hombres cuyo trono esperaba poder ocupar, como $\mathrm{Fe}$ derico II Staufen, que había vivido en una corte cosmopolita en la que se rodeó de sabios, filósofos y matemáticos como Miguel Scotto, Juan de Palermo o Leonardo de Pisa, el rey castellano patrocinó una amplia producción cultural y consiguió mantener una corte propia que poco o nada tenía que envidiar a la de los emperadores.

Tal vez el rey sabio no consiguiera nunca ser coronado emperador, pero algunos investigadores, como Robert I; Burns, no han dudado en atribuirle el título de emperador de la cultura. Si su sueño político nunca vio la luz y su política interna llegó incluso a ser considerada como ineficaz, no se puede negar que la cultura bajomedieval, e incluso renacentista en algunos campos específicos, quedó fuertemente marcada por su intervención.

En este sentido debemos subrayar que la actividad cultural favorecida por el rey sabio se organizó según dos ejes mayores.

El primero de ellos es sin duda el desarrollo del castellano. 


\section{La producción del scriptorium}

La elección de una lengua vernácula en detrimento del latín parece haber sido la expresión lógica de un programa político de gran envergadura. Las ambiciones imperiales de Alfonso X, así como el conjunto de sus obras legislativas de las que hablaremos más adelante, nos permiten comprender que el rey deseaba establecer una política unificadora sobre la cual construir una sociedad regida por leyes homogéneas y en la que todos tuvieran unos referentes culturales comunes. En este contexto, se puede considerar que el latín era la lengua de la Iglesia y por lo tanto podía ser considerado como una herramienta discriminatoria hacia la cultura hebrea y musulmana. Sin llegar a concluir que la elección del castellano se debió a una influencia más o menos directa de los judíos de la corte, "poco amigos de la lengua litúrgica de los cristianos", puesto que ello sería atribuirles un poder y una influencia que es poco probable que tuvieran, sí podemos considerar que el monarca favoreció el castellano como herramienta para forjar un referente cultural común para los fieles de las tres religiones del Libro. Se trataba, sobre todo, de dar una coherencia general a su reino.

Es evidente que la lengua castellana ya era empleada en los cantares de gesta (Mío Cid) y en el siglo XIII la cancillería de Fernando III ya emitía algunos documentos oficiales en castellano, mientras el mester de clerecía se caracterizaba por usar el román paladino en sus composiciones. El castellano ya tenía por lo tanto una historia cuando Alfonso X subió al trono, pero no había alcanzado aún la perfección necesaria para transformarse en una herramienta válida de investigación y de enseñanza. Este paso se dio gracias a la voluntad del rey sabio por poner al alcance de sus vasallos el conjunto de los conocimientos humanos.

Por supuesto, la utilización de una lengua vernácula iba a limitar la difusión de estas obras, sin embargo, algunas de ellas han podido adquirir una importancia internacional por su carácter extraordinario. Y es así como llegamos al segundo eje de la actividad cultural alfonsí, caracterizado por la extensa producción de libros.

Aunque la temática de los trabajos que salieron del scriptorium alfonsí es muy variada, se pueden distinguir dos tipos de producción: algunas obras son creaciones genuinas, mientras que otras son traducciones de obras más antiguas. Ahora bien, una traducción no significa ausencia de creación personal; si por una parte la transposición al castellano derecho, como lo describía el monarca, fue la motivación principal para el perfeccionamiento de éste, al afinar la lengua y poder así expresar nuevos matices, por otra fue también una ocasión para

${ }^{1}$ Rafael LAPESA, Historia de lengua española, Gredos, Madrid, 1988, p.237. 


\section{Daniel Grégorio}

mejorar las obras traducidas, aportando correcciones y comentarios a los textos originales.

No es extraño que Alfonso X conociera la importancia de la traducción en la búsqueda del saber.

Recordemos que, en el conjunto de la Europa medieval, la producción científica se limitaba a una compilación general en latín de obras anteriores. Sin embargo, en Al-Andalus, desde los tiempos del califato Omeya, los científicos habían conseguido realizar una producción propia que destacó sobre todo en el ámbito de las ciencias exactas. Los reinos cristianos de la península, cerca de la frontera, supieron aprovechar sus contactos con el califato.

La inquietud intelectual del rey sabio estimuló su interés por la cultura árabe. Por ello, en 1254, Alfonso X estableció en Sevilla, su ciudad preferida, un Estudio General que debía facilitar el estudio de la civilización y la cultura árabes.

Para llevar a cabo el conjunto de traducciones necesarias para la incorporación de los datos contenidos en las obras árabes, Alfonso X supo aprovechar la experiencia y las estructuras de la Escuela de Traductores de Toledo, fundada en la primera mitad del siglo XII. En estas primeras traducciones, el castellano se transformó en un puente, un lazo entre el árabe y el latín, de forma que poco a poco tuvo que adaptarse y evolucionar con el fin de mejor transmitir los matices y las nociones expresadas por el documento fuente.

Dentro del estricto respeto del método empleado por la Escuela de Traductores, desde tiempos de Juan Hispalense y de Domingo Gundisalvo (Tabla 1), la obra original era traducida por un colaborador que dominaba el árabe y poseía cierta erudición en el tema tratado por el texto fuente. Entre otros, encontramos en los prólogos alfonsíes los nombres Jehuda Ben Moses Cohen, médico personal del rey, Isaac Ibn Cid, traductor de la Escuela de Toledo o incluso Bernardo el Arábigo, un converso. Estos primeros colaboradores realizaban una traducción oral en castellano que dictaban a un segundo traductor cuyo objetivo era realizar, por escrito, una versión latina de la traducción oral que le estaban dando. Este segundo equipo estaba compuesto por traductores de Toledo como Álvaro de Oviedo, o notarios del rey como Juan de Cremona, e incluso religiosos como Garci Perez. Sin embargo, Alfonso X introdujo una novedad en esta cadena de producción al añadir al equipo de traductores un escriba que dejaba constancia de la versión castellana. Rápidamente, Alfonso X centró los esfuerzos de traducción en la versión castellana, relegando a un segundo plano, incluso a veces suprimiendo, la versión latina. 


\section{La producción del scriptorium}

Ahora bien, la simple traducción de trabajos más antiguos no habría bastado para dar al castellano su fuerza y su maleabilidad lingüística. Una vez realizada la primera versión, había que pulir la lengua, reagrupar las nociones y suprimir, según voluntad real, las partes ilógicas. El rey en persona parece haber intervenido en esta segunda fase de creación ya que el prólogo de la Ochava Esfera nos dice que el rey quitó "las razones que entendió eran sobejanas y dobladas y que no eran en castellano derecho, y puso las otras que entendió que cumplían; y el lenguaje, enderezólo el por sí mismo".

En cualquier caso, la primera parte de la traducción era un trabajo que reunía a hombres de culturas, orígenes y creencias diferentes. Es seguramente este aspecto el que dio a la corte alfonsí todo su esplendor y su reputación internacional.

La importancia intelectual de estas traducciones se comprende mejor si consideramos que la noción de novedad o de producción personal no era la misma en la Edad Media que hoy en día.

Es necesario distinguir las nociones de ayuntador, de comentador y de autor, que quedan fuertemente ligadas a las nociones de vetustas, es decir de antigüedad, y de auctoritas, es decir de sabiduría reconocida y considerada como una garantía de autenticidad. Cualquier producción medieval se fundamenta en una o varias obras anteriores, consideradas como fuentes de sabiduría, avaladas por la antigüedad (vetustas) del escrito y por la fama o reputación (auctoritas) del autor. Sin embargo, el comportamiento del intelectual medieval no es en modo alguno pasivo ante estas obras. El comentador, retomará la obra original para aclarar puntos oscuros, mientras que el autor utilizará estas mismas obras para intentar hacer avanzar la producción. Sin embargo esta última acción no define del todo la noción de autoría.

Para mejor comprender esta noción es necesario analizar como se compusieron las obras genuinas del rey sabio.

Si en los prólogos de las traducciones siempre es posible encontrar el nombre del autor y el papel que jugó el monarca en su realización, las obras originales plantean el problema de determinar la auténtica autoría de las mismas. Tal vez el problema sea la propia definición del termino autor, que hoy en día asimilamos a la persona que crea materialmente la obra. En la Edad Media la cosa no era tan sencilla. Demos como ejemplo el nacimiento del estilo gótico, que se atribuye al abad Suger (1081-1151) que se presenta como el auténtico auctor de las innovaciones arquitectónicas de su iglesia sin nombrar jamás al arquitecto que realizó realmente la construcción y que concibió las técnicas necesarias para el desarrollo del nuevo estilo. 


\section{Daniel Grégorio}

Algo similar ocurrió con las obras atribuidas a Alfonso X, aunque esta vez el monarca castellano no olvidó mencionar la existencia de todo un equipo de colaboradores.

En efecto, el prólogo de la General Estoria nos recuerda que "el rey hace un libro, no por que él lo escriba con sus manos, mas por que compone las razones de él, y las enmienda, y yegua, y endereza, e muestra la manera de como se deben hacer, (...) decimos por esta razón que el rey hace el libro". En otras palabras, el rey es el autor porque dirige y vigila las operaciones de creación. De este prólogo podemos pues concluir que lo que llamamos autoría de Alfonso X era sobre todo una labor organizadora y directora, y que el rey, si llegó a corregir la expresión, es poco probable que tomara él mismo la pluma, contentándose con dictar a sus amanuenses los comentarios y rectificaciones que le parecían oportunos, como lo demuestran varias miniaturas de presentación de autor en sus manuscritos.

En todas ellas (Lapidario, Cantigas de Santa María, Libros de juegos, dados y tablas) podemos observar cómo el rey adopta la representación clásica del magister de la Antigüedad, es decir que tiene mayores proporciones u ocupa un lugar más elevado en el conjunto y se caracteriza, sobre todo, por ese dedo índice que apunta hacia el texto que está explicando o hacia la copia que quiere corregir, como símbolo de su sabiduría.

El conjunto de la producción alfonsí parece ser pues una síntesis de los trabajos de los sabios del pasado para ofrecer una visión de conjunto de los conocimientos de la humanidad, muchas veces adaptados a las necesidades del momento o puestos al día según la visión del mundo de aquella época. Esta búsqueda del saber caracteriza lo que se podría llamar el enciclopedismo medieval, cuyas obras más significativas podrían ser la Doctrina Christiana de San Agustín (396426), que pretendía un mayor acercamiento a Dios por un mejor conocimiento de la Naturaleza, las Etimologías de san Isidoro de Sevilla, por las que el santo doctor intentó organizar, en el siglo VII, los saberes históricos, matemáticos y lingüísticos del momento en veinte capítulos distintos, sin olvidar el Speculum Majus de Vincent de Beauvais, que reunió en el siglo XIII los escritos de diferentes eruditos griegos, romanos y hebreos. A partir del siglo XIII, el enciclopedismo se centra en la selección y organización de los saberes, y por ello la obra de Alfonso X podría inscribirse también en esta corriente.

Dejando de lado la distinción entre traducciones y obras propias, podemos destacar cuatro áreas principales en la creación del scriptorium alfonsí. 
La primera es, sin duda, el campo científico, que para la Edad Media tenía mucho que ver con las matemáticas y una astronomía fuertemente teñida por consideraciones astrológicas.

Entre 1250 y 1280 , Alfonso X ordenó una serie de traducciones que exponían gran parte de las bases de la ciencia medieval, así como de la concepción que se tenía por entonces de las fuerzas naturales.

En conjunto se tradujeron más de veinte tratados, de entre los cuales podemos destacar el Lapidario (1250-1279) compuesto por cuatro libros en los que se describen las propiedades físicas y astrológicas de 360 minerales. Por otra parte, obras como el Libro de los juicios de las estrellas y el Picatrix (1256), El libro de la Açafea (1256), El libro de la ochava esfera (1256-1276), El libro de las cruces y la Alcora (1256), se centran sobre todo en el estudio de los astros. Tal vez de entre ellos los más significativos sean los Libros del saber de Astrología (1276-1279) que intentan sintetizar las doctrinas de Ptolomeo, del mismo modo que las Tablas alfonsinas (1256-1277), a partir de las observaciones realizadas en el siglo XIII, intentan corregir las Tablas de Azarquiel, un astrónomo del siglo XI.

Todos estos manuscritos nos hablan de cierta armonía celeste, de la esencia de los minerales y de los medios para comprender y estudiar los planetas. En ellos se pueden encontrar los fundamentos de la astrología y de la astronomía, con ciertos elementos mágicos muy marcados. En efecto, algunas obras como el Lapidario o el Picatrix explican la influencia de los astros sobre las piedras y las propiedades de éstas en un contexto próximo a la magia talismánica.

Gracias a las obras científicas, Alfonso X intentó definir mejor el mundo en el que vivía. El espíritu de estos trabajos podría resumirse por la frase que cierra el prólogo del Lapidario, obra traducida para que cualquier ser humano "obrando de esta guisa (llegue) a lo que quisiera hacer por ellas".

A pesar de no poder abandonar cierto tipo de superstición, estas traducciones tuvieron como consecuencia más directa el desarrollo innegable de la astronomía y contribuyeron en cierta forma al establecimiento de las bases de otras ciencias como la geología.

Estos trabajos consolidaron los fundamentos de una observación que se puede considerar como científica, es decir metódica, gracias a un instrumental, preciso para la época, basado en las descripciones realizadas por Ptolomeo (100-170) en su Almagesto. Tal vez la consecuencia más importante de esta observación rigurosa de la naturaleza sea justamente la corrección de las tablas de Azarquiel, compuestas en el siglo XI. Esta corrección realizada en la propia corte alfonsí trans- 


\section{Daniel Grégorio}

formó las tablas de Azarquiel en las Tablas Alfonsinas, una obra cuya fama rebasó rápidamente las fronteras hispánicas y que fue utilizada en casi toda Europa hasta el siglo XVI, cuando la astronomía adoptó definitivamente el sistema heliocéntrico de Copérnico, abandonando el sistema ptolemáico.

Mientras los libros de astronomía, aunque fuertemente influidos por la astrología, intentan mostrar el lugar que el hombre ocupa en el mundo material, otras obras aportan conocimientos históricos y filosófico-morales.

Tal vez la necesidad de colocar el ser humano en el tiempo igual que intentó colocarlo en el espacio, haya sido el origen de las creaciones realizadas entre 1260-1284.

El scriptorium alfonsí participó en esta búsqueda del tiempo pasado. Produjo así la Crónica General, centrada en la historia de la Península Ibérica, y la Grande e General Estoria, una obra mucho má ambiciosa que debía recoger toda la historia humana desde la Creación hasta el siglo XIII. Esta última obra fue redactada, como lo indica su prólogo, "porque el saber del tiempo que fue es cierto, y non de los otros dos tiempos (...) trabajáronse los sabios hombres de meter en escrito los hechos que son pasados para haber remembranza de ellos, como si entonces fuesen y que lo supiesen los que habían de venir así como ellos".

La ambición de estos proyectos exigía le reunión de datos y de fuentes, realizada por los ayuntadores, así como el estudio, la síntesis y la organización final de todos los elementos.

Los amanuenses que debían dar la forma final de estas obras eran seguramente cristianos, pero si consideramos la diversidad y la extensión de las fuentes utilizadas, no podemos más que reconocer el interés alfonsí por las otras culturas. Así, el rey castellano realizó su obra histórica refiriéndose siempre a sabios de la Antigüedad (Aristóteles, Plinio, Ovidio, Suetonio) a eruditos judíos (Flavio Josefo) y utilizando además fuentes más recientes como el De Rebus Hispaniae o Historia Gothica (1242) de Rodrigo Jiménez de Rada, el Toledano, y el Chronicon Mundi (1236) de Lucas de Tuy, el Tudense.

El propio monarca nos confirma la utilización de varias fuentes puesto que en el mismo prólogo de la General Estoria confiesa: "Después que hube hecho ayuntar muchos escritores y muchas historias de los hechos antiguos, escogí de ellos los más verdaderos y de los mejores que supe; e hice entonces hacer este libro, y mandé poner en él todos los hechos señalados". 
En este sentido es interesante subrayar que contrariamente a otros monarcas como San Luis de Francia, el nombre de Alfonso X no está ligado a ninguna obra de carácter litúrgico. Sin embargo, en la Grande e General Estoria, se encuentra la Biblia Alfonsina, es decir, una traducción al castellano de la Vulgata utilizada aquí como fuente histórica y no por su valor litúrgico.

Así pues, el monarca castellano era consciente de la necesidad de dar a sus súbditos las herramientas adecuadas, tanto científicas como históricas, para poder construir una sociedad equilibrada. Por ello no nos ha de extrañar que también quisiera proporcionarles un corpus legislativo adecuado.

En este contexto, las obras legislativas, como el Setenario, el Espéculo y las Siete Partidas forman el hábeas legislativo de un reino con múltiples tradiciones.

El Setenario parece haber sido una obra iniciada por Fernando III el santo; no se trata tanto de una obra puramente legislativa, aunque tenga cierta semejanza con la Primera Partida, como de una obra didáctica, de enseñanza teológica y moral para reyes.

En lo que se refiere a los textos puramente legales es necesario empezar por el Espéculo (1254) que expone de forma global el derecho según se concebía y aplicaba en la corte alfonsí.

Aunque el más importante es, por supuesto, el códice de la Siete Partidas o Libro del fuero de las leyes escrito entre 1256 y 1265.

Las primeras líneas de las Siete Partidas, redactas "a servicio de Dios y a pro comunal de todos (...) porque los que lo leyesen hallasen en él todas las cosas cumplidas y ciertas para aprovecharse de ellas", dejan adivinar una voluntad organizadora que proporcionaría un código legal que regiría la vida de todos los componentes del reino.

Así, la Primera Partida empieza por dar una explicación sobre el concepto de ley, de uso y costumbre, para centrarse después en el papel de la Iglesia en la sociedad, así como en sus fundamentos teológicos y el respeto que se debe a las diversas manifestaciones de la fe cristiana. Dentro del concepto gelasiano de las dos espadas, según el cual la potestas regalis debía proteger la auctoritas pontificalis, el rey expresa aquí los diferentes crímenes que se han de castigar, desde la simonía hasta los sacrilegios, recordando los fundamentos del buen comportamiento de un clérigo.

La Segunda Partida se centra sobre todo en la vida, la función y las responsabilidades del rey. A modo de espejo, este capítulo abarca tanto el comportamiento que ha de tener el monarca con su familia como los diferentes aspectos a tener en cuenta para dirigir su reino. 


\section{Daniel Grégorio}

De estos aspectos, la Tercera Partida destaca sobre todo el sistema judicial y administrativo, mientras la Cuarta versa sobre la familia y presta especial atención a la organización social del reino, contemplando el estatuto de los vasallos y de los siervos o considerando los problemas de los hijos ilegítimos y de la educación.

Tras el análisis moral, legislativo y social, la Quinta y Sexta Partidas proponen un conjunto de leyes puramente económicas y laborales que, salvando las distancias, podrían representar un primer intento de intervensionismo estatal en la vida económica de una sociedad.

Por último, la Séptima Partida abarca los temas aún no evocados, es decir todo aquello que se refiere a los componentes más o menos alejados de la sociedad cristiana. Son analizados aquí los derechos y obligaciones de los judíos y de los musulmanes, considerados en conjunto como elementos integrantes de la sociedad económica, aunque no de la comunidad espiritual. Se condenan igualmente los comportamientos heréticos y las actividades de las brujas, así como cualquier uso indebido de la fuerza, desde los retos hasta los simples homicidios, pasando por la aplicación del tormento.

Las Siete Partidas son, por su extensión, el código legislativo más importante de la Edad Media, basado en el Derecho Romano, en el código Justiniano y en las obras de Isidoro de Sevilla y de Aristóteles entre otros.

Aunque la labor legislativa de Alfonso X puede considerarse como la realización de una proyecto ya ideado por su padre Fernando III, no es imposible pensar que semejante obra, dividida en siete capítulos que corresponden a las siete letras del nombre del monarca (Tabla 2) pudiera ser el símbolo más visible de su voluntad por alcanzar la dignidad imperial.

A estas preocupaciones de vida social y común se añaden otras de orden más filosófico o sencillamente literario.

Así, obras como el Calila e Dimna (1251-1252) representan una traducción de cuentos morales orientales creados para la educación moral de nobles y príncipes, de la misma forma que, fruto del interés por la cultura árabe, la Escala de Mahoma (1251-1252?, 1263) representa una exégesis del periplo de Mahoma narrado en la azora 17 del Corán.

Las obras alfonsíes querían aparentemente abarcar todos los aspectos de la actividad intelectual humana, tanto individual como social, así como procurar las herramientas necesarias para la educación de los dirigentes del reino. No es pues de extrañar que Alfonso X también promoviera el Libro de ajedrez, dados y tablas (1274?-1283) que 
representa la obra más importante para la época en lo que concierne el juego de ajedrez y que en cierta forma podría ser considerado como el precursor de los problemas de ajedrez publicados en los periódicos. El impacto de esta obra sobrepasa el simple marco del ocio, ya que representa también una introducción al mundo de la táctica guerrera, un mundo en el que la traición no existe pero en el que la realidad cotidiana y la amargura del vencido quedan expresadas de forma simple. En efecto, el juego de ajedrez queda resumido por el monarca castellano en "cómo dar jaque al Rey, que es el mayor trabajo de todos (...) es una manera de enfrentarse al Señor con derecho, y de cómo le dan mate que es una manera de gran deshonra, así como si lo venciesen o matasen”. Esta reflexión que puede traducir el estado de ánimo del rey ante la oposición nobiliaria, nos recuerda el comentario del propio Alfonso X, para quien los nobles "no se movieron contra (él) por razón de fuero ni por tuerto que les tuviese... Por pro de la tierra no lo hacen... mas la razón porque lo hicieron fue esta: por querer tener siempre los reyes apremiados y levar de ellos lo suyo".

Así pues la obra alfonsí, sin alejarse de los problemas cotidianos y de los avatares de la vida política del reino, reagrupa casi todos los saberes humanos. Dejó a los castellanos una síntesis general de conocimientos del momento; gracias a ella podrían regirse y mejor conocer la creación de Dios así como su propio lugar en la Naturaleza. A este proyecto unificador del interior del reino podría también atribuírsele un proyecto de propaganda por el cual el monarca pudiera demostrar, en el ámbito de su política exterior, que era el mejor candidato para el trono imperial.

Por otra parte, si las artes del Trivium y del Quadrivium debían ser representadas en su totalidad, la poesía y la música no podían quedar abandonadas.

La producción literaria de Alfonso X se compone de unos cuarenta poemas profanos: 35 poemas de escarnho, que critican un enemigo político o un rival en amores, 4 tençós que evocan una disputa o manifiestan una oposición de ideas, así como 4 poemas de amor.

Ningún colaborador judío parece haberse asociado a la redacción de estas obras, sin embargo pueden también demostrar la participación de colaboradores de orígenes diversos.

Estas últimas obras se inscriben efectivamente en la corriente poética de los trovadores, y nos recuerdan que el monarca acogió a poetas procedentes de otros países, como Gonzalo Eanes do Vinhal y Airas Núnez, ambos gallegos, o aún el narbonés Guiraut de Riquier. Se confirma, pues, así que la corte del rey sabio era un lugar de en- 


\section{Daniel Grégorio}

cuentro intelectual, un lugar en el que diferentes culturas, tradiciones y nacionalidades podían compartir sus experiencias. Esta capacidad por aceptar la pluralidad de ideas explica en parte la fama internacional que tuvo.

A esta producción profana se deben añadir las Cantigas de Santa María, una obra de corte espiritual centrada en la colección de milagros atribuidos a la Virgen.

Mientras las cantigas profanas son la prueba de un interés del rey por el mundo que lo rodea y por los atractivos humanos que existen en él, las Cantigas de Santa María demuestran la importancia que el monarca reservaba a la salvación del alma. El rey no podía desestimar el alma del hombre si quería reunir todos los temas que interesaban a sus vasallos; así, las Cantigas completan la obra alfonsí, aunque se distinguen de los otros escritos por la lengua utilizada.

Mientras el conjunto de las obras hasta aquí evocadas queda redactado en castellano, las Cantigas utilizaron una lengua mucho más lírica, más apta para la creación poética. Fueron redactadas en gallego, y se alimentaron tanto de relatos anteriores, esencialmente los de Berceo, Coincy, Adgar y Beauvais, como de narraciones propias que refieren milagros acaecidos en toda Europa.

La colección de las Cantigas ha sido definida por Menéndez Pelayo como "una Biblia estética del siglo XIII", y ello se comprende por la belleza de las miniaturas que acompañan cada poema. Pero, además, estas ilustraciones otorgan a la colección alfonsí una personalidad, una esencia, mucho más intensa que la que se puede encontrar en las demás obras. En efecto, las Cantigas no son una simple sucesión de narraciones, como pueden serlos los Milagros de Nuestra Señora de Berceo. Gracias la distribución de las páginas miniadas el conjunto adquiere una coherencia propia.

El conjunto general se organiza sobre una secuencia decenal (nueve poemas de milagros y uno de loor). En el interior de esta secuencia se observa una segunda organización, pues todos los poemas van acompañados por seis miniaturas, salvo aquellos que se encuentran en quinta posición que, además de ser más largos, van ilustrados por doce miniaturas dispuestas en una doble página. La elección del quinto poema como elemento clave se explica por su correspondencia con las cinco letras del nombre de María. De esta forma se obtiene una secuencia particular $(4+1+4+$ loor $)$ que confiere al conjunto una cadencia propia, y que podría recordar la estructura del rosario.

En conjunto podemos observar que Alfonso X demostró un espíritu universal y una voluntad sistematizadora del saber expresada por 
la inmensa producción realizada bajo su dirección. Esta voluntad fue sin duda fortalecida por el sueño imperial que requería un comportamiento universal, una visión y una personalidad que rebasara cualquier frontera política o cultural. El carácter cosmopolita de la corte castellana queda expresado por la acogida que reservaba el monarca a poetas y astrónomos extranjeros y cuya influencia directa sobre la creación del rey fue decisiva.

Por supuesto, la motivación esencial de este comportamiento y de estas creaciones, literarias, científicas, históricas o legislativas, no puede limitarse a una simple inquietud intelectual o a un altruismo sin medida; como lo hemos dicho, el contexto socio-político no podía más que influir en las decisiones del monarca. Por ello, el desarrollo del castellano y la producción general de las obras alfonsíes responden a una doble exigencia del momento. Al dar una lengua común, una cultura común a todos sus vasallos, el monarca podía esperar una consolidación de su poder fundado en su intervención centralizadora. Pero podía también demostrar que tenía las cualidades necesarias, el carisma y el reconocimiento suficiente de sus semejantes para presentar su candidatura y obtener la corona imperial.

La diversidad de los temas tratados en el conjunto de las obras escritas, traducidas o compiladas bajo la dirección de Alfonso X, revela la sed de conocimientos del monarca así como su visión particular de lo que debía ser su reino y las bases sobre las que debía ser construido. Tal vez su fracaso político no se debiera tanto una incapacidad para gobernar o a una concepción idealista de la sociedad, como a una visión vanguardista de la misma. Y es tal vez por ello, por su voluntad de conocer mejor su pasado y su presente, para construir un futuro mejor, que Alfonso X merece, sin duda, el título de sabio.

Tabla 1. Trabajo en la escuela de traductores, época del arzobispo don Raimundo (s. XII)

\begin{tabular}{|l|l|l|l|l|}
\hline & $\begin{array}{l}\text { Traductor } \\
\text { mozárabe } \\
\text { o judío }\end{array}$ & $\begin{array}{l}\text { Traductor } \\
\text { cristiano }\end{array}$ & \\
\hline Hispalense & & $\begin{array}{l}\text { Domingo } \\
\text { Gundisalvo }\end{array}$ & \\
\hline $\begin{array}{l}\text { Texto } \\
\text { en } \\
\text { árabe }\end{array}$ & & $\begin{array}{l}\text { Versión oral } \\
\text { castellana }\end{array}$ & $\begin{array}{l}\text { Texto } \\
\text { en } \\
\text { latín }\end{array}$ \\
\hline
\end{tabular}


Daniel Grégorio

Scriptorium Alfonsí (s. XIII)

\begin{tabular}{|l|l|l|l|l|}
\hline & $\begin{array}{l}\text { Traductor } \\
\text { mozárabe } \\
\text { o judío }\end{array}$ & $\begin{array}{l}\text { Traductor } \\
\text { cristiano }\end{array}$ & \\
\hline $\begin{array}{l}\text { Mehuda Ben } \\
\text { Moses Cohen } \\
\text { Isaac Ibn Cid } \\
\text { Bernardo el } \\
\text { Arábigo } \\
\text { Samuel Leví }\end{array}$ & $\begin{array}{l}\text { Versión } \\
\text { oral } \\
\text { castellana }\end{array}$ & $\begin{array}{l}\text { Alvaro de Oviedo } \\
\text { Juan de Cremo- } \\
\text { na } \\
\text { Garci Perez } \\
\text { Guillén Arremón } \\
\text { de Aspa } \\
\text { Juan de Aspa } \\
\text { Juan de Mesina }\end{array}$ & \\
\hline $\begin{array}{l}\text { Texto } \\
\text { en ára- } \\
\text { be }\end{array}$ & & $\begin{array}{l}\text { Texto } \\
\text { castellano }\end{array}$ & & \\
\hline
\end{tabular}

Tabla 2: Acróstico en las Siete Partidas

\begin{tabular}{|l|c|l|}
\hline Primera Partida & A & $\begin{array}{l}\text { A servicio de Dios y a pro comunal de } \\
\text { todos hacemos este libro.... }\end{array}$ \\
\hline Segunda Partida & $\mathbf{L}$ & $\begin{array}{l}\text { La fe católica de Nuestro Señor Jesu- } \\
\text { cristo hemos mostrado.... }\end{array}$ \\
\hline Tercera Partida & $\mathbf{F}$ & $\begin{array}{l}\text { Fizo Nuestro señor Dios todas las co- } \\
\text { sas muy cumplidamente... }\end{array}$ \\
\hline Cuarta Partida & $\mathbf{O}$ & $\begin{array}{l}\text { Obras señaladas dio nuestro señor } \\
\text { Dios al hombre sobre las otras criatu- } \\
\text { ras... }\end{array}$ \\
\hline Quinta Partida & $\mathbf{N}$ & $\begin{array}{l}\text { Nacen entre los hombres mucho enje- } \\
\text { cos y grandes contiendas.... }\end{array}$ \\
\hline Sexta Partida & $\mathbf{S}$ & $\begin{array}{l}\text { Sesudamente dijeron los sabios anti- } \\
\text { guos que sobrepasan su tiempo... }\end{array}$ \\
\hline Séptima Partida & $\mathbf{O}$ & $\begin{array}{l}\text { Olvido y atrevimiento son dos cosas } \\
\text { que hacen a los hombres errar mu- } \\
\text { cho... }\end{array}$ \\
\hline
\end{tabular}


La producción del scriptorium

\section{BIBLIOGRAFÍA}

Colectivo, Les échanges culturels au Moyen Âge, Paris (Publication de la Sorbonne) 2002.

CHEJNE, Anwar, Historia de la España musulmana, Madrid (Cátedra) 1999.

de LIBERA, Alain, Penser au Moyen Âge, Paris (Seuil) 1991.

GERBET, Marie-Claude, L'Espagne au Moyen Âge, Paris (Armand Colin) 1992.

IRADIEL, Paulino, MORETA, Salustiano \& SARASA, Esteban, Historia medieval de la España cristiana, Madrid (Cátedra) 1995.

MACKAY, Angus, La España de la Edad Media, Madrid, Cátedra, 1995.

MARTIN, Hervé, Mentalités Médiévales, Paris (PUF) 1998.

MENÉNDEZ PIDAL, Gonzalo, La España del siglo XIII leída en imágenes, Madrid (Real Academia de la Historia) 1986.

MENÉNDEZ PIDAL, Gonzalo, Varia Medievalia, 2 vols, Madrid (Real Academia de la Historia) 2003.

MONTOYA, Jesús \& DOMÍNGUEZ RODRÍGUEZ, Ana, El scriptorium alfonsí: de los libros de Astrología a las Cantigas de Santa María, Madrid (Universidad Complutense) 1999.

MUNDI Franciso \& SAENZ Anabel, Las prosificaciones de las Cantigas de Alfonso X el Sabio, Barcelona (PPU) 1987.

O'CALLAGHAN, Joseph, El rey sabio: el reinado de Alfonso $X$ de Castilla, Sevilla (Universidad de Sevilla) 1996.

PROCTER, Evelyn, Alfonso X de Castilla, Patrono de las letras y del saber, Murcia (Real academia Alfonso X el Sabio) 2002.

RODRÍGUEZ LLOPIS, Miguel, Alfonso X: aportaciones de un rey castellano a la construcción de Europa, Murcia (Conserjería de Cultura y Educación) 1997.

SALVADOR MARTÍNEZ, H, Alfonso X el sabio, una biografía, Madrid (Ediciones Polifemo) 2003. 